\title{
Temporal-Spatial Pattern and Influencing Factors of China's Province-Level Transport Sector Carbon Emissions Efficiency
}

\author{
Zhimin Peng, Qunqi Wu, Dongfang Wang, Min Li* \\ School of Economics and Management, Chang'an University, Middle Section of South Second Ring Road, \\ Xi'an, Shaanxi, China
}

Received: 15 June 2018

Accepted: 27 December 2018

\begin{abstract}
The transport sector, as an industry with high energy consumption and high carbon emissions, plays an increasing role in achieving the goal of carbon emissions reduction in China. Understanding the situation of the transport sector's carbon emissions efficiency and the relevant dominating driving forces is an important prerequisite for formulating carbon emissions reduction polices. This study evaluated the transport sector carbon emissions efficiency of 30 provinces in China from 2004 to 2016 using the Super slacks-based measure (Super-SBM) model,which employs Moran's I indexand spatial econometric approaches to examine its spatial dependence and the dominating driving factors. The results are shown as follows. Firstly, the transport carbon emissions efficiency had a noticeable disparity across the provinces and regions, and the spatial distribution characteristic of transport sector carbon emissions efficiency could be described as "high in the east and low in the west". Secondly, transport sector carbon emissions efficiency presented significant spatial dependence and clustering characteristics, and the pattern evolutions of spatial distribution presented a path-dependence effect to some extent. Thirdly, the regression results of the spatial Durbin model (SDM) indicated that the per-capita GDP and transportation energy consumption structure had significantly positive effects on transport sector carbon emissions efficiency, whereas the urbanization, transportation intensity, transportation energy intensity, and transportation service structure hada negative effect on transport sector carbon emissions efficiency.
\end{abstract}

Keywords: carbon emissions efficiency, spatial dependence, Moran's I index, spatial econometric analysis, transport sector, China

*e-mail: mins205@163.com 


\section{Introduction}

Since the reform and opening up in 1978, China's economy has maintained a trend of rapid development in general. From the second quarter of 2010, China's total economic output exceeded that of Japan and become the second largest economy in the world. However, the achievement of economic development was largely based on the high consumption of resources and high emissions of pollution [1]. China has been the largest greenhouse gas emitter since 2007, and surpassed the United States in 2010 to become the largest energy consumer in the world [2]. The resulting environmental deterioration not only affects the health of the people, but also threatens the sustainable development of the country in the future.

Transportation, as a high energy consumption sector $[3,4]$, is a major contributor to carbon emissions in each country [5]. From a global perspective, in the total energy consumption of the world, the transport sector accounts for one-third [6]. Meanwhile, according to the China Statistical Yearbook, in 2015 the relevant energy consumption in China's transport sector was 383 million tons of standard coal equivalent (CE), which maintained a relatively high growth rate in the past 10 years. It can be seen that the transport sector has increasingly become a key industry for China to fulfill the commitment of reducing carbon emissions. The sustainability of energy-saving and environmental protection is largely related to the improvement of efficiency during the production process [7]. Improving environmental efficiency is increasingly important for achieving the goal of carbon emissions reduction $[8,9]$. Therefore, it has great practical significance for evaluating China's transport sector carbon emissions efficiency.

It is worth noting that due to the remarkable disparity among the provincial natural geography, the scale of population, and the socio-economic development level, the problems faced by each provincial transport sector in the process of energy conservation and carbon emissions reduction are also quite different. However, the relevant studies indicate that geography is an important issue that cannot be neglected in the research of environmental quality (especially for air pollution) [10]. Importantly, except for the geography conditions, the socio-economic factors are also interrelated and interact in different regions. That is, the inter-regional dependence and spatial spillover effects of different regions have a significant influence on China's provincial economic development [11]. For example, as pointed out by Chuai et al. [12], the level of economic development in the surrounding areas will lead to a certain regional correlation of energy consumption and carbon emissions. Furthermore, for the carbon emissions policies, reduction formulated by regional governments also have a certain correlation and significant positive externalities. In other words, the measures of transport carbon emissions abatement adopted in a region will generate a positive externality of the neighboring provinces. Therefore, under this background, it seems to be necessary to further analyze the spatial dependence of provincial transport sector carbon emissions efficiency as well as the main driving factors.

A large number of studies focus on the evaluation of carbon emissions efficiency in the transport sector, and the influencing factors analysis explain why there were discrepancies in transport sector carbon emissions. The methods of measuring carbon emissions efficiency can be divided into the single factors, like energy intensity [13], carbon emissions intensity [14], and multiplefactors, generally. However, the single-factor indicator approaches just evaluate the partial performance of carbon emissions because the total factors do not take into account the production system. For this reason, the data envelopment analysis (DEA) method is commonly used to evaluate the carbon emissions efficiency based on the framework of total factor production [2]. As for China's transport sector, some scholars have proposed the relevant model based on the DEA model to evaluate transport environmental efficiency. For example, Chang et al. [15] proposed a non-radial DEA model with the slacks-based measure(SBM) to measure the environmental efficiency in China's transport sector. Liu et al. [16] proposed a parallel Slack-Based measure (SBM) data envelopment analysis (DEA) model to evaluate the overall efficiency of the land transportation sector. Zhou et al. [17] examined the energy efficiency performance of China's transport sector based on the data envelopment analysis (DEA) approach with considering undesirable outputs.

Meanwhile, existing studies have paid extensive attention to the dominant driving factors of transport sector carbon emissions, and the relevant research methods can be divided into two categories, generally. The first research method is the index decomposition method, which is also the most commonly used. Greening et al. [18] analyzed the 10 OECD countries' carbon emissions change in the freight sector from 1970 to 1993 . They found that the increase in carbon emissions intensity for nine countries is mainly due to the shifts in modal structure toward more carbon-intensive transportation modes. Mazzarino [19] found that growth in the economy was the main driving factors for Italy's transport sector carbon emissions during the period 1970-1993. Timilsina and Shrestha [20] found that economic development and transportation energy intensity play a dominant role in 20 Latin American and Caribbean (LAC) countries' transport sector carbon emissions during the period 1980-2005. Andreoni and Galmarini [21] found that the European water and aviation transport sector carbon emissions are mainly determined by transportation energy intensity and economic growth. Achour and Belloumi [22] found that the scale of economy and population, transportation intensity, and energy intensity play a positive effect on Tunisia‘s transport 
sector carbon emissions growth. Wang et al. [23] found that the per-capita GDP and transport modal shifts are the main driving factors for China's transport sector carbon emissions during the period 1985-2009. Loo and Li [24] analyzed the influencing factor in passenger transportation carbon emissions in China since 1949; they found that per-capita income level is, firstly, responsible for carbon emissions growth. The second research method is the econometric model. Using the vector autoregressive (VAR) model, Talbi [25] found that the improvement of energy efficiency and fuel rate have a positive influence on Tunisia's road transport sector carbon emissions reduction. Zhang et al. [26] found that electrification and energy efficiency improvement are effective in reducing the transport sector carbon emissions reduction in China. Liao et al. [27] found that the economic growth and oil price are to be responsible for carbon emissions growth for the inland container transport by using the multiple regression models.

The previous studies have enriched our understanding of the transport carbon emissions efficiency and its main influencing factors. However, there were few studies that focus on the temporalspatial distribution characteristics of transport carbon emissions efficiency and the influencing factors analysis from the spatial econometric approaches. Especially for the influencing factors analysis, the above studies did not take the spatial interaction effects into consideration and the relationship of the relevant variables are based on the assumption of spatial independence. As pointed out by Le Sage et al. [28], the characteristics of a local region will be affected by the adjacent regions to some extent. Furthermore, it may lead to the estimation bias on the regression results for the conventional estimation techniques when ignoring the spatial interaction effects according to "the first law of geography" [29]. Meanwhile, the relevant studies have indicated that the significant spatial dependence of carbon emissions cannot be ignored [30-32]. To fill such a research gap, we will study China's province-level transport sector carbon emissions efficiency based on the spatial effects perspective. Specifically, we analyzed the spatiotemporal distribution pattern of transport sector carbon emissions efficiency based on the panel data from 2004 to 2016. Additionally, we examined spatial dependence and analyzed the dominating driving factors. To our knowledge, this study is the first attempt to investigate the dominant driving factors of transport sector carbon emissions efficiency using the spatial econometric approaches. It is expected that such research can provide the scientific basis for decision-making in formulating the regional transport sector carbon emissions reduction policies to a certain extent.

Compared to the existing literature, this study has three possible contributions. Firstly, unlike the previous studies that employed the method of single factors to evaluate the carbon emissions efficiency, we used the method of super-SBM based on the DEA model to measure transport carbon emissions efficiency, which is better to analyze the influencing factors. Secondly, unlike the previous studies that neglected the spatial dependence of transport carbon emissions efficiency, we employed the method of Moran's I index to evaluate the spatial autocorrelation and analyze the temporal-spatial distribution pattern. Finally, unlike the previous studies that employed the traditional econometric approaches, we employed the spatial econometric approaches to analyze the driving factors of transport carbon emissions efficiency.

\section{Materials and Methods}

\section{Variables and Data Resource}

\section{Calculation for Carbon Emissions Efficiency}

Due to the increasing attention to environmental issues, a large number of studies [33-35] take the undesirable output, such as carbon dioxide, waste water, and waster gas, into consideration on evaluating the environmental efficiency based on the traditional DEA model in the transport sector. Here we employed the Super-SBM model to calculate China's provincelevel transport sector carbon emissions efficiency. We assumed that the transportation production system has $n$ decision making units, each with three factors: input, desirable outputs, and undesirable outputs, and is described by three vectors: $x \in R^{m}, y^{g} \in R^{s_{1}}, y^{b} \in R^{s_{2}}$, respectively. We define the matrices $X, Y^{g}$, and $Y^{b}$ as follows:

$$
\begin{aligned}
& X=\left[x_{1}, \mathrm{~L}, x_{n}\right] \in R^{m \times n}>0 \\
& Y^{g}=\left[y_{1}^{g}, \mathrm{~L}, y_{n}^{g}\right] \in R^{s_{1} \times n}>0 \\
& Y^{b}=\left[y_{1}^{b}, \mathrm{~L}, y_{n}^{b}\right] \in R^{s_{2} \times n}>0
\end{aligned}
$$

Then the production possibility set $(P)$ can be defined by:

$$
P=\left\{\left(x, y^{g}, y^{b}\right) \mid x \geq X \lambda, y^{g} \leq Y^{g} \lambda, y^{b} \geq Y^{b} \lambda, \lambda \geq 0\right\}
$$

Based on function $P$, and according to Tone's SBM model [36], the SBM model is as follows:

$$
\begin{aligned}
& \rho=\min \frac{1-\frac{1}{m} \sum_{i=1}^{m} s_{i}^{-} / x_{i 0}}{1+\frac{1}{s_{1}+s_{2}}\left(\sum_{r=1}^{s_{1}} s_{r}^{g} / y_{r 0}^{g}+\sum_{l=1}^{s_{2}} s_{l}^{b} / y_{l 0}^{b}\right)} \\
& \text { s.t. } \quad x_{0}=X \lambda+s^{-} \\
& y_{0}^{g}=Y^{g} \lambda-s^{g} \\
& y_{0}^{b}=Y^{b} \lambda+s^{b} \\
& s^{-} \geq 0, s^{g} \geq 0, s^{b} \geq 0, \lambda \geq 0
\end{aligned}
$$

...where the objective function $\rho$ denotes the carbon emissions efficiency value of DMU $\left(x_{0}, y_{0}{ }^{g}, y_{0}{ }^{b}\right) ; m, s_{1}$, 
and $s_{2}$ stand for the number of factors for input, desirable and undesirable outputs, respectively; $s^{-}, s^{g}$ and $s^{b}$ refer to the slacks in the input, desirable and undesirable outputs, respectively; $\lambda$ is the intensity vector. The object function $\rho$ has values in the range $[0,1]$. If $\rho=1$, it means the decision making unit is SBM-efficient and if $0 \leq \rho<1$, it means the decision making unit is SBM-inefficient.

However, most empirical results of efficiency evaluation research indicated that plural decision making units are SBM-efficient at the same time [37]. Therefore, how to reasonably distinguish these SBM-efficient DMUs is critical to efficiency ranking, especially for the dominant driving factors analysis of carbon emissions efficiency. Therefore, to more accurately evaluate the transport sector carbon, According to the research of $\mathrm{Li}$ et al. [38], the Super-SBM model is used to evaluate the SBM-efficient DMUs:

$$
\begin{array}{ll}
\rho^{*}= & \min \frac{\frac{1}{m} \sum_{i=1}^{m} x_{i} / x_{i 0}}{\frac{1}{s_{1}+s_{2}}\left(\sum_{r=1}^{s_{1}} y_{r}^{-g} / y_{r 0}^{g}+\sum_{l=1}^{s_{2}} y_{l}^{-b} / y_{l 0}^{b}\right)} \\
\text { s.t. } \quad & -x \geq \sum_{j=1, \neq 0}^{n} \lambda_{j} x_{j} \\
& \quad-g \quad \leq \sum_{j=1, \neq 0}^{n} \lambda_{j} y_{j}^{g} \\
& y_{0}^{b} y \geq \sum_{j=1, \neq 0}^{n} \lambda_{j} y_{j}^{b} \\
& -\quad \geq x_{0}, y^{-g} \geq y_{j}^{g}, y^{-b} \geq y_{j}^{b}, y^{-g} \geq 0, \lambda \geq 0
\end{array}
$$

...where $\rho^{*}$ is the objective function whose value can be more than 1 , and the other variables have the same meaning as in Eq. (3). In general, The Super-SBM model described above has three main advantages. First, it can effectively solve the slackness problem of input and output factors. Second, it is particularly suitable for dealing with undesirable outputs. Third, it effectively solves the problem of distinguishing and ranking the SBM-efficient DMUs in the SBM model.

\section{Input and Output Indicators}

Based on the model described above, we will employ the Super-SBM model to calculate the transport sector carbon emissions efficiency change of 30 provinces in mainland China from 2004 to 2016 (excluding Tibet because of the absence of relevant data). The input and output indicators are described below.

Input indicators: Based on economic growth theory, labor and capital are the basic and core input factors. Therefore, we chose the number of employed labor in transport sector as the labor input. As for the capital input, the most commonly used indicator is the capital stock, but due to the official statistics on this indicator not being available in China, a feasible solution is to replace the capital stock with the amount of fixed capital investment as some scholars did [39, 40]. Meanwhile, this study mainly chooses the relevant fuel consumption (including raw coal, coke, crude oil, gasoline, kerosene, diesel, fuel oil, liquefied petroleum gas, and natural gas) in the transport sector as energy inputs, and all kinds of energy types are translated into standard coal equivalent using the National Standard Conversion Coefficient of China.

Output indicators: We chose gross domestic product by transportation as the desirable output, while the amount of the transport sector carbon emissions from energy consumption are chosen as the undesirable output. Owing to the fact that official statistics on provincial-level carbon emissions from the transport sector are not available in China, we will employ the method described in reference [41] to calculate the amount of transport carbon emissions.

According to China's Statistical Yearbooks and the China Energy Statistical Yearbook, the data resource of the transport sector in China derives from the data of transport, storage, and post. From the availability of the data, we follow the method to collect the relevant data as most scholars did [42]. Meanwhile, the monetary indicators, including the amount of fixed capital investment and gross domestic product by transportation, are converted into year 2004 constant prices using the fixed capital investment price index and the third industry added value deflators, respectively. Table 1 shows the descriptive statistics for the input and output indicators.

\section{Independent Variables}

Based on the data availability and the relevant literature, per-capita GDP, urbanization, transportation intensity, transportation energy intensity, transportation service structure, and transportation energy consumption structure were chosen to be the dominant driving factor of transport sector carbon emissions efficiency.

Per-capita GDP (PGDP) refers to the gross domestic product divided by the total population, which reflects the economic development scale effects on carbon emissions. The environmental Kuznets curve theory indicates that economic development is the most important factor influencing carbon emissions, and there is a nonlinear relationship between economic development and carbon dioxide emissions [43].

Urbanization (UR) refers to the proportion of the permanent residents of an urban area in a region to the total resident population in that region according to the National Bureau of Statistics of China. A large number of empirical studies show that the process of urbanization has resulted in very large energy consumption and subsequent worldwide environmental concerns [44]. Meanwhile, urbanization may be an important factor influencing carbon emissions in the transport sector [45]. 
Table 1. Descriptive statistical characteristics of input and output indicators.

\begin{tabular}{|c|c|c|c|c|c|c|}
\hline Inputs and outputs & Variable & Unit & Min & Max & Mean & Std. dev. \\
\hline \multirow{2}{*}{ Non-energy input } & Capital stock & $10^{8}$ Yuan & 35.51 & 726.67 & 272.34 & 162.66 \\
\cline { 2 - 7 } & Labor employment & $10^{4}$ persons & 2.01 & 63.55 & 16.53 & 10.28 \\
\hline Energy input & Energy consumption & $10^{4}$ tons of SCE & 23.89 & 3069.69 & 799.17 & 567.34 \\
\hline Desirable output & GDP by transport sector & $10^{8}$ Yuan & 30.00 & 2961.12 & 727.33 & 561.18 \\
\hline Undesirable output & Carbon emissions & $10^{4}$ tons & 61.07 & 6680.93 & 1763.26 & 1231.73 \\
\hline
\end{tabular}

Transportation intensity (TI) refers to the ratio of comprehensive transportation service and the added value in transport sector, which reflects the economic efficiency of the transport sector. According to $\mathrm{Yu}$ et al. [46], the comprehensive transportation service is defined as the sum of passenger kilometers and freight kilometers. According to the statistical methods of the Ministry of Transport of China, the conversion coefficients of passenger kilometers to freight kilometers for railway, highway, waterway, and civil aviation transportation modes are 1.0, 0.1, 0.33, and 0.09, respectively. An increase in the transportation intensity can reduce carbon emissions and improve transport sector carbon emissions efficiency [23].

Transportation energy intensity (TEI) refers to the ratio of the transport sector total energy consumption and the comprehensive transportation service, which reflects the efficiency of energy utilization in the transport sector. A decrease in transportation energy intensity indicates an improvement in the efficiency of energy utilization and the technological progress level in the transport sector [47].

Transportation service structure (TSS) refers to the proportion of the highway comprehensive transportation service to the total comprehensive transportation service. As a high-carbon emissions-intensive transportation mode (in terms of carbon emissions per passenger/ freight kilometers), highway transportation accounts for a majority of the transport sector carbon emissions in China [5]. A feasible and effective solution to improve the transport sector emissions efficiency could be modal shifting, that is, from highway transportation to lower carbon emissions-intensive transportation modes, such as railway and water transportation.

The transportation energy consumption structure (TECS) refers to the proportion of coal consumption to total energy consumption in the transport sector. Different fuels have different carbon contents, which lead to a significant difference in the contribution of carbon emissions. Coal, as a high carbon content energy, pays primary responsibility for China's energy consumption for production needs [48]. Therefore, we assume that a decrease in the proportion of coal consumption can improve transport sector carbon emissions efficiency.

Thus, the classical econometric model of transport sector carbon emissions efficiensy can be given as:

$$
\begin{aligned}
\ln C E E_{i t}= & C+\beta_{1} \ln P G D P_{i t}+\beta_{2} \ln U R_{i t}+\beta_{3} \ln T I_{i t}+\beta_{4} \ln T E I_{i t} \\
& +\beta_{5} \ln T S S_{i t}+\beta_{6} \ln T E C S_{i t}+\mu_{i t}
\end{aligned}
$$

...where CEE refers to the transport sector carbon emissions efficiency, $C$ refers to the constant, $\beta$ refers to the estimation coefficient, $\mu_{i t}$ refers to the error term, $i$ refers to the province $i$ and $t$ refers to the year $t$.

\section{Spatial Econometrics Model}

\section{Global Spatial Autocorrelation}

In practice, spatial dependence is commonly examined by the global Moran I index method [49]. In this study, we also employ it to examine the spatial dependence of transport sector carbon emissions efficiency. Concretely, the global Moran I index can be expressed as:

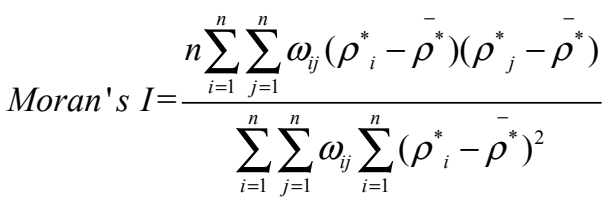

...where $n$ denotes the number of geographical units, that is, the provinces we researched in this study; $\bar{\rho}^{*}$ stands for the average value of $\rho^{*}$; and $\omega_{i j}$ is the element in the spatial weight matrix $W$, which describes the spatial relationship corresponding to the geographic districts $(i, j)$. In this study, we will adopt the most widely used spatial weight matrix: the binary contiguity matrix [50]. For provinces $i$ and $j$, which are adjacent to each other, then the spatial weight matrix element $\omega_{i j}$ will be assigned a weight of 1 , otherwise $\omega_{i j}$ will be assigned a weight of 0 . Meanwhile, the global Moran I index has values in the range $[-1,1]$, If $0<$ Moran's $I \leq 1$, which means a positive spatial dependence; if $-1<$ Moran's $I<0$, which means a negative spatial dependence; and Moran's $I=0$ means there is no spatial correlation.

\section{Model Specification}

Following Elhorst [51], three spatial econometric models have been commonly used to describe the spatial dependence, including spatial lag model 
(SLM), spatial error model (SEM), and spatial Durbin model (SDM). The SLM adds the spatial lag terms of the dependent variable to the non-spatial panel model, which hypothesizes that the value of the dependent variable observed in a region is affected by the value of the neighboring dependent variable. That is, the transport sector carbon emissions efficiency in the province is affected by the carbon emissions efficiency of neighboring provinces. The SLM is defined as:

$$
Y=\varphi W Y+X \beta+\varepsilon
$$

...where $X, Y$ stands for the vector of independent variable and dependent variable; $\varphi$ is the spatial autoregressive coefficient; and $\varepsilon$ is normally distributed disturbance term with a diagonal covariance matrix. The SEM considers the spatial dependence of the error term. The SEM is defined as:

$$
Y=X \beta+\varepsilon \quad \varepsilon=\gamma W \varepsilon+\mu
$$

...where $\mu$ and $\gamma$ denote the spatial dependence of the error term and its spatial autoregressive coefficient, respectively. The SDM adds the spatial lag terms of the dependent variable and independent variable to the non-spatial panel model. The SDM is defined as:

$$
Y=\varphi W Y+X \beta+W X \phi+\varepsilon
$$

...where $\phi$ denotes the spatial autoregressive coefficient on independent variables. Meanwhile, we will follow the test method outlined by Elhorst [51] to test which of SLM, SEM and SDM is more appropriate. Firstly, we estimate the classical econometric model and test the joint significance of spatial fixed effects and timeperiod fixed effect. Then we employ the LM spatial lag

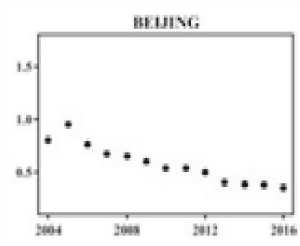

HaMTh:

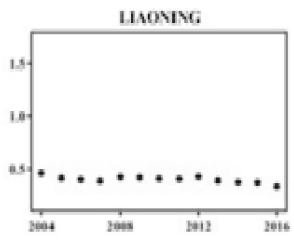

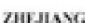

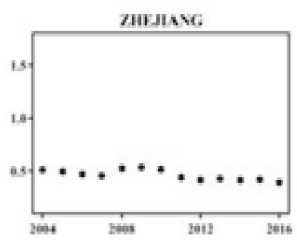

III)

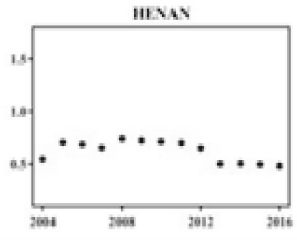

IISIX)

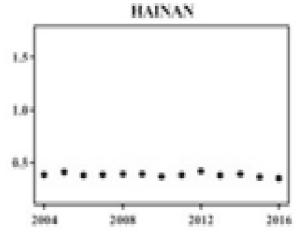

SHM⿻日木

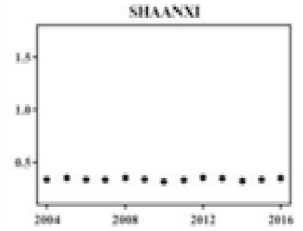

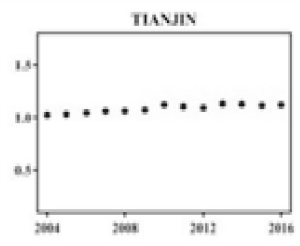

JIIIT

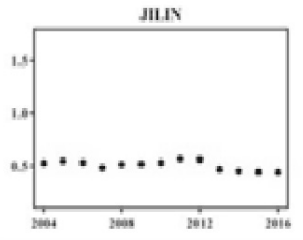

มIII

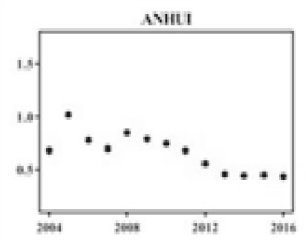

นเศน

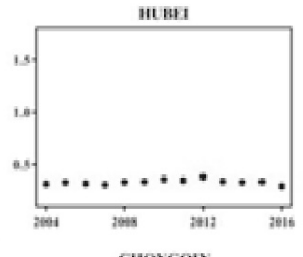

chovoess

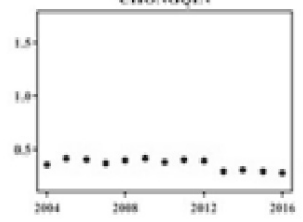

Gast

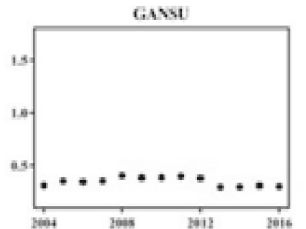

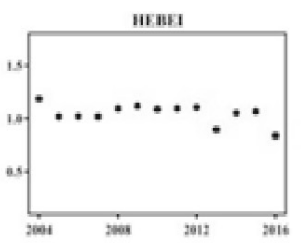

HIKOMEHAMG

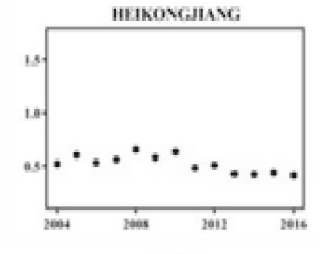

nuns
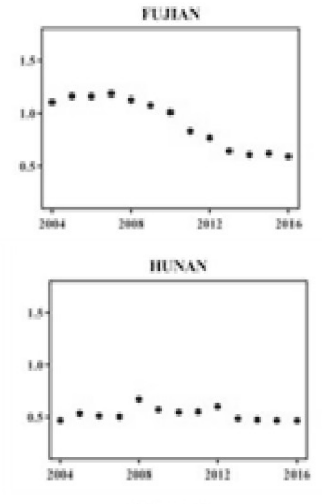

SICIIA

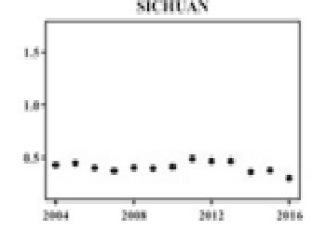

Oाพत)

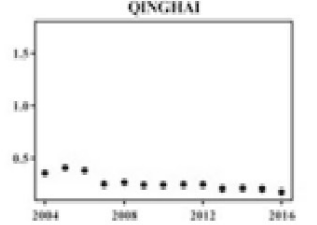

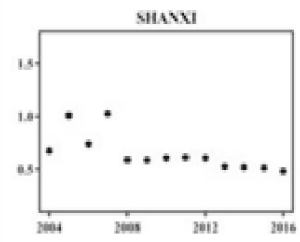

SHAvGILI
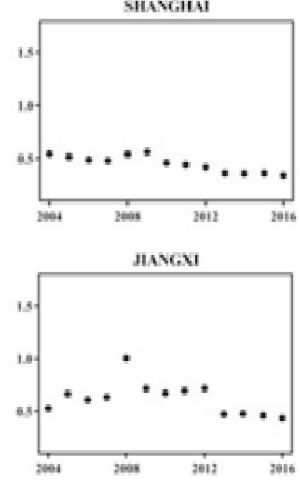

GLAMGOON,
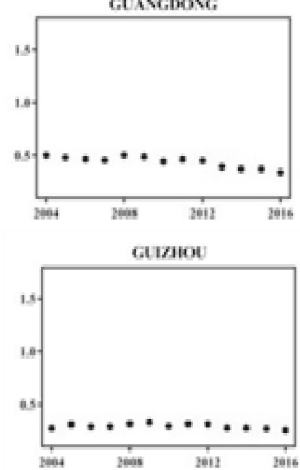

MIMGXIA

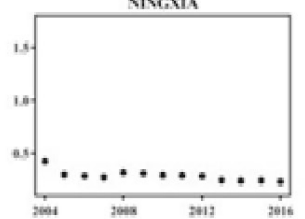

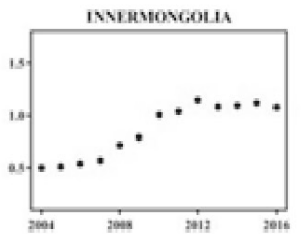

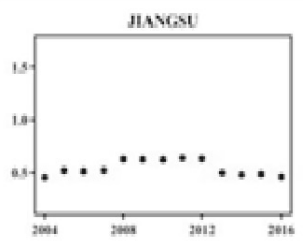

SHAvenow:
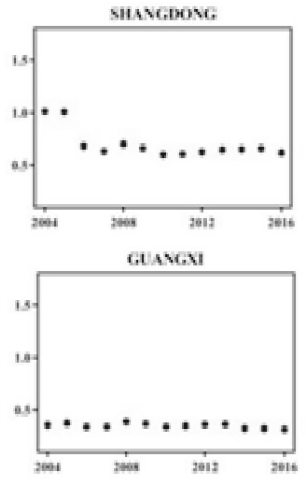

vหra

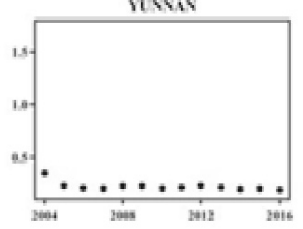

XINJus:

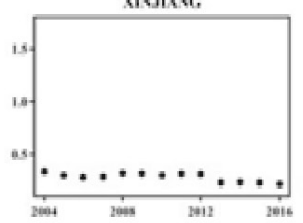

Fig. 1. Provincial transport sector carbon emissions efficiency in China from 2004 to 2016. 
and LM spatial error and their robustness to test whether the spatial effects models are better than the non-spatial panel model or not. Secondly, we employ the Wald test and LR test method to examine whether the SDM can be simplified to the SLM or SEM. The two null hypotheses: $H_{0}: \phi=0$ and $H_{0}: \phi+\varphi \cdot \beta=0$ are used to test for determining which spatial econometric model should be chosen. If the first null hypothesis $H_{0}: \phi=0$ is rejected by Wald test, then the SDM can be simplified to the SLM; and if the second null hypothesis $H_{0}: \phi+\varphi \cdot \beta=0$ is rejected by the LR test, then the SDM can be simplified to the SEM. If the first null hypothesis and the second null hypothesis are both rejected, then we can consider that the SDM is more acceptable.

\section{Results and Discussion}

\section{Spatial Distribution Characteristics of Carbon Emissions Efficiency}

Fig. 1 clearly shows the tendency of the China province-level transport sector carbon emissions efficiency from 2004 to 2016. The maximum value appeared in Hebei Province in 2004, where the corresponding carbon emissions efficiency was 1.1881. The minimum value appeared in Qinghai in 2016, the corresponding carbon emissions efficiency was 0.1772 . The three provinces with the highest value of average carbon emissions efficiency were Tianjin, Hebei, and Fujian; and the three lowest provinces were Yunnan, Qinghai and Xinjiang. The results showed that the average carbon emissions efficiency of the transport sector in Tianjin is 4.84 times that of Yunnan. It can be seen that the provincial transport sector carbon emissions efficiency had an obvious difference. Furthermore, the average value of carbon emissions efficiency in China's transport sector is 0.5157 , the overall carbon emission efficiency is low. Those results indicated that China's transportation industry has not yet formed an effective coordination between environmental protection and economic development, but it also means that China's transportation industry has a greater space for resource conservation and environmental protection improvement in the future development process.

The disparity in the transport sector carbon emissions efficiency also showed the spatial
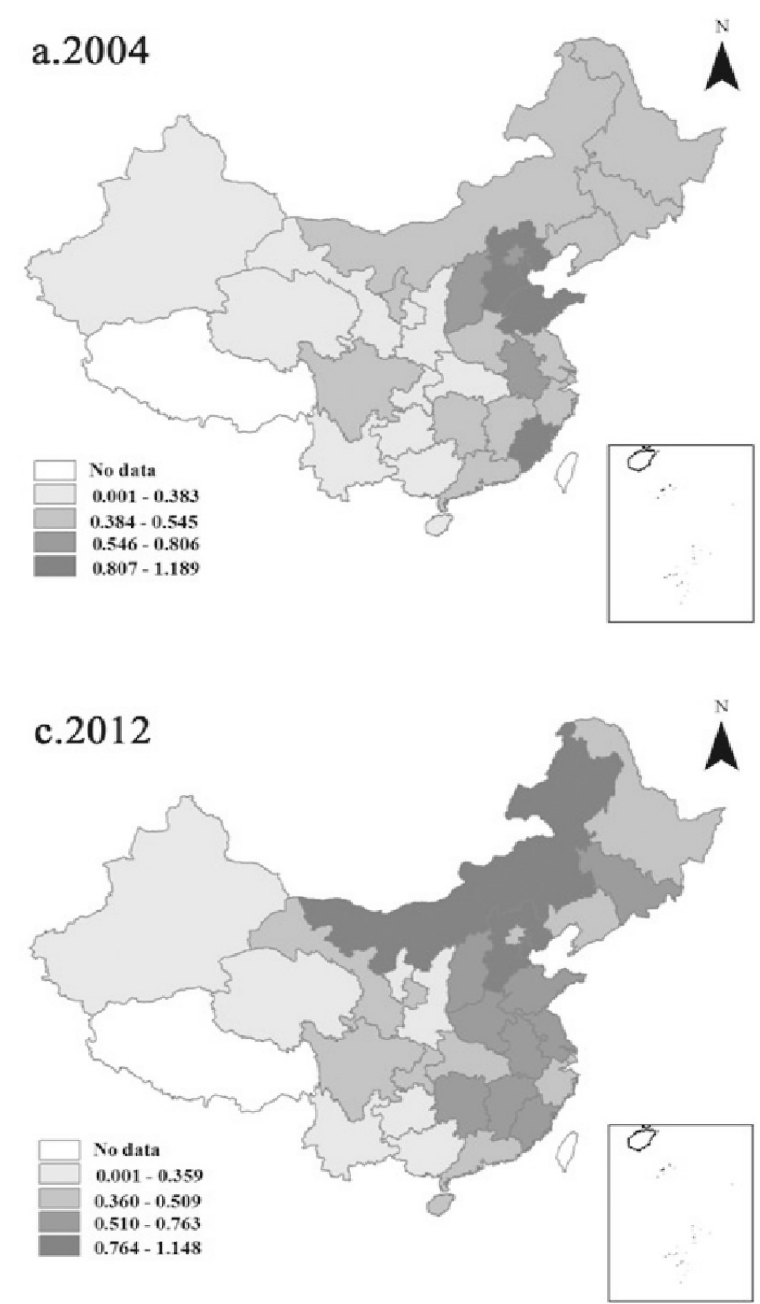
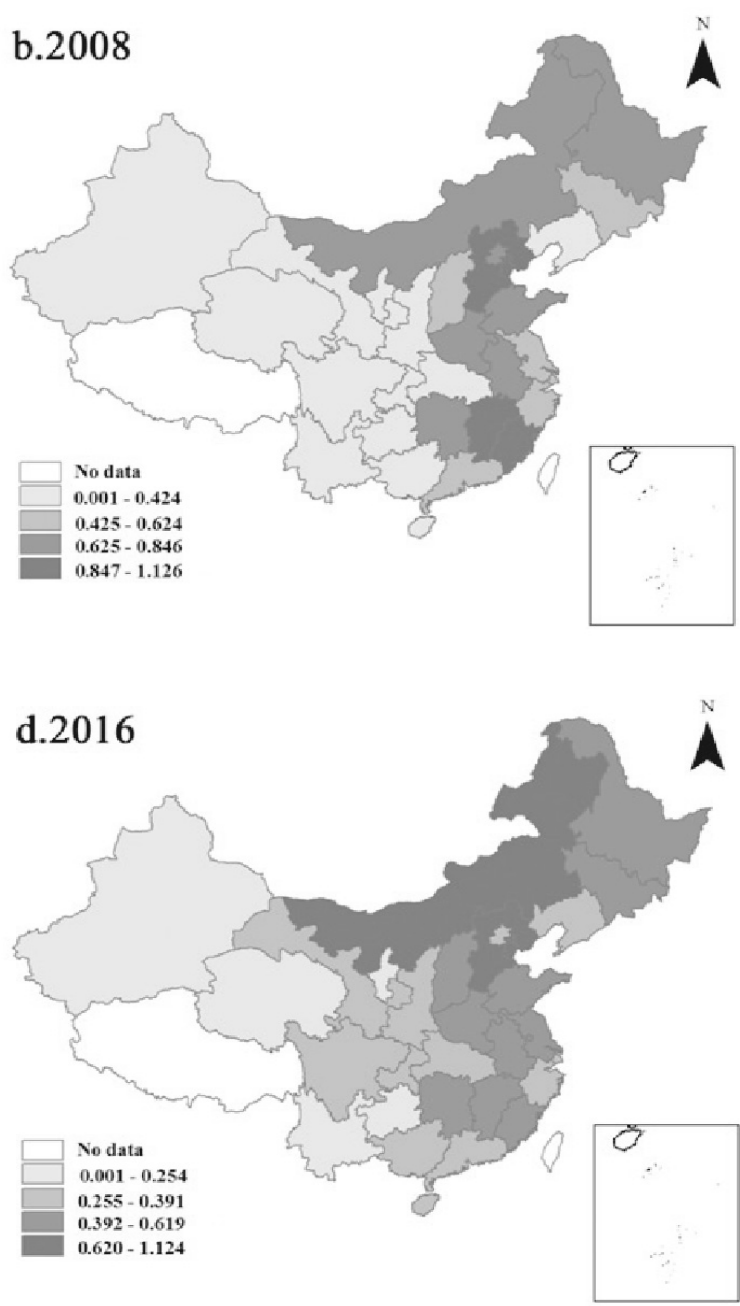

Fig. 2. Quartile graphs of transport sector carbon emissions efficiencies through time. 
Table 2. Global Moran I index of transport sector carbon emissions efficiency.

\begin{tabular}{|c|c|c|c|c|c|c|c|}
\hline Year & Moran's I & P-value & $\mathrm{Z}$ & Year & Moran's I & P-value & Z \\
\hline 2004 & 0.442 & 0.001 & 4.632 & 2011 & 0.325 & 0.002 & 3.063 \\
\hline 2005 & 0.431 & 0.001 & 4.148 & 2012 & 0.301 & 0.001 & 2.837 \\
\hline 2006 & 0.431 & 0.001 & 4.094 & 2013 & 0.255 & 0.001 & 2.641 \\
\hline 2007 & 0.405 & 0.003 & 3.474 & 2014 & 0.304 & 0.001 & 3.615 \\
\hline 2008 & 0.411 & 0.001 & 4.074 & 2015 & 0.298 & 0.001 & 3.101 \\
\hline 2009 & 0.409 & 0.001 & 3.819 & 2016 & 0.263 & 0.001 & 2.504 \\
\hline 2010 & 0.359 & 0.004 & 3.579 & & & & \\
\hline
\end{tabular}

Notes: The symbol * denotes $\mathrm{P}<0.1$, ** denotes $\mathrm{P}<0.05$, *** denotes $\mathrm{P}<0.01$.

dependence. Due to the limitation of space, this study just listed the quartile graphs of the transport sector carbon emissions efficiency in the years 2004, 2008, 2012, and 2016. As shown in Fig. 2, the provincial transport carbon emissions efficiency had great spatial differences and clustering characteristics. For example, at the beginning of the observation period (2004), the five highest provinces were Hebei, Fujian, Tianjin, Shandong, and Beijing, while Shaanxi, Xinjiang, Hubei, Gansu, and Guizhou had the lowest carbon emissions efficiency. At the end of the observation period (2016), the five highest provinces were Tianjin, Inner Mongolia, Hebei, Shandong, and Fujian while Guizhou, Ningxia, Xinjiang, Yunnan, and Qinghai had the lowest carbon emissions efficiency. Overall, the transport sector carbon emissions efficiencies of the eastern provinces were higher than the central and western provinces. Specifically, the average carbon emissions efficiency in eastern, central, and western provinces was 0.6373 , 0.5561 , and 0.3646 , respectively (three regional division methods can be found in reference [17]). The spatial distribution characteristic of transport sector carbon emissions efficiency can be described as a "threestep" spatial pattern, that is, high in the east and low in the west. This indicates that there may be a certain correlation between the transport sector carbon emission efficiency and the socio-economic development level.
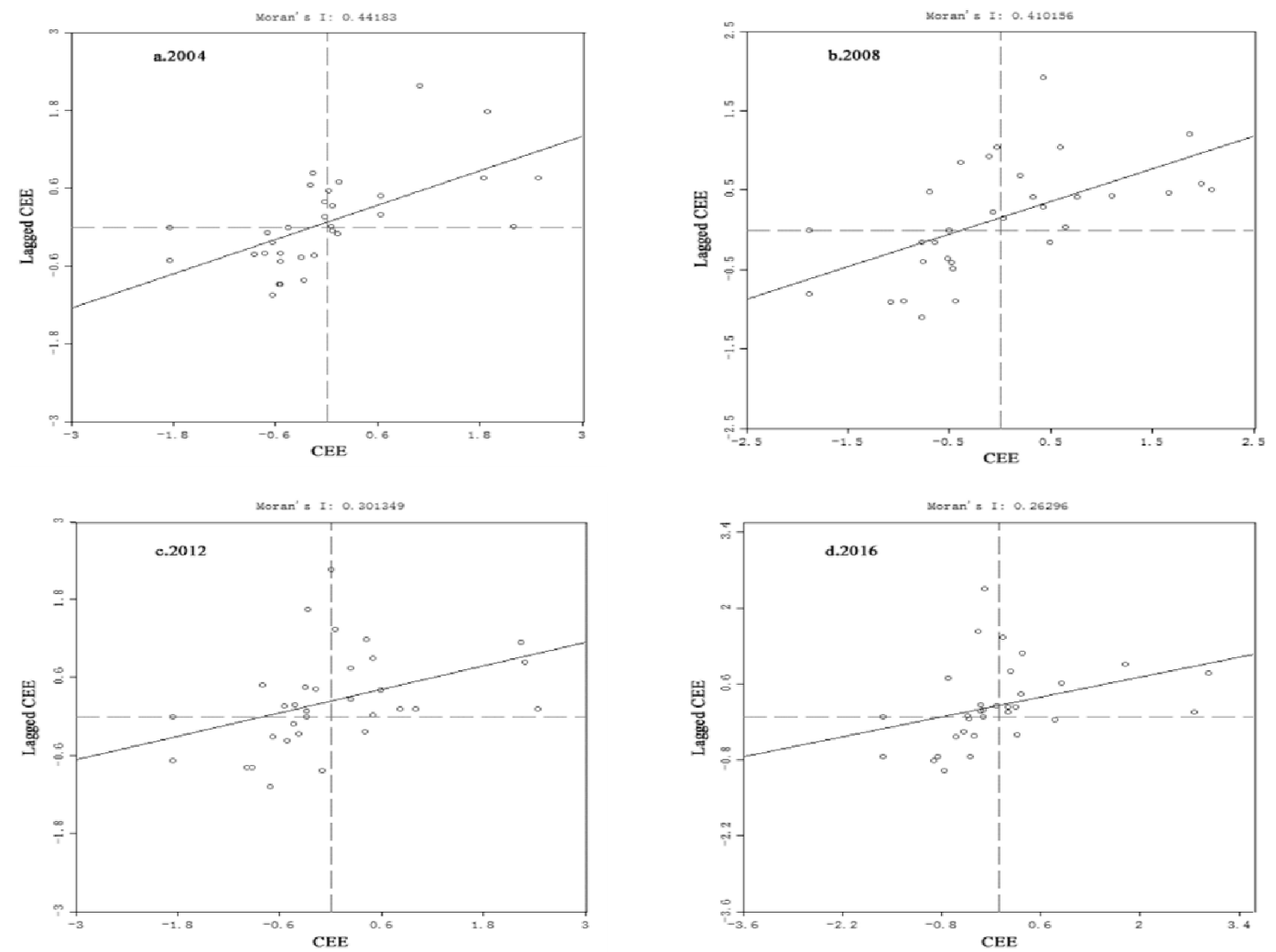

Fig. 3. Moran I scatter plots of the transport sector carbon emissions efficiencies through time. 


\section{Global Spatial Autocorrelation}

As shown in Table 2, the annual Moran I index showed the positive value and passed the significance test at the $1 \%$ level. It can be seen that the transport sector carbon emissions efficiency showed a significant spatial autocorrelation. The geographic distribution of the transport sector carbon emissions efficiency tended to cluster together. Meanwhile, the value of global Moran's I index of carbon emissions efficiency showed a declining trend ranging from 0.442 to 0.263 , which indicated that the spatial clustering degree had a decreasing tendency. However, the global Moran's I index can just be used to examine the average correlation degree overall [48]. When some provinces show the positive effects, whereas the other present the negative effects, the global Moran index may reveal non-spatial autocorrelation because the spatial effects may offset each other. Therefore, we further employed the Moran I scatter plot method to further examine the spatial autocorrelation and the clustering characteristics of the transport carbon emissions efficiency in 2004, 2008, 2012, and 2016.

As shown in Fig. 3, the horizontal axis of the Moran I scatter plot denotes the carbon emissions efficiency, and the vertical axis denotes the corresponding spatial lag. There are four quadrants with corresponding clustering characteristic in the Moran I scatter plot: quadrant I with a High-High (HH) clustering characteristic, quadrant II with a Low-High (LH) clustering characteristic, quadrant III with a Low-Low (LL) clustering characteristic, and quadrant IV with a High-Low (HL) clustering characteristic. Meanwhile, the $\mathrm{HH}$ and LL clustering indicate positive spatial autocorrelation. The LH and HL clustering indicate the negative spatial autocorrelation characteristics. In years 2004, 2008, 2012, and 2016 there were 23 provinces $(76.67 \%), 23$ provinces $(76.67 \%), 21$ provinces $(70 \%)$, and 19 provinces $(63.33 \%)$ that show positive spatial autocorrelation, respectively. This indicated that the improvement of the transport sector carbon emissions in the above provinces will have significant positive externalities of the neighboring provinces. Meanwhile, the results indicated that the provinces in quadrant I were mainly distributed in the eastern and central region, whereas the provinces in quadrant III were mainly distributed in the western region. This result further indicated that transport sector carbon emissions efficiency had a significant spatial clustering characteristic. Additionally, there were some provinces that presented a negative spatial autocorrelation, as well. For example, Shanghai, Beijing, Liaoning, Hainan, Guangdong, Hubei, and Ningxia located in quadrant II, and Hunan and Fujian located in quadrant IV, in 2016. Furthermore, compared to the year 2004, in 2016, the number of provinces that belonged to quadrants I and III decreased by four, while the number of provinces that belonged to quadrants II and IV increased by four. This showed that the spatial clustering degree of the transport sector carbon emissions efficiency seemed to be weakening. The results of global Moran I index and Moran I scatter plot indicated that there was a significant spatial autocorrelation of the transport sector carbon emissions efficiency during the observation period.

Meanwhile, in order to further reveal the dynamic spatial distribution characteristics of carbon emissions efficiency in China's transport sector, we employed the space-time transition method proposed by Rey [52] in order to depict the transfer of Moran I scatter plots between the different local agglomeration areas. Table 4 presents the space-time transition matrices of Moran I plot of carbon emissions efficiency in 3 time periods. As shown in Table 4, the space-time transition of provinces mainly occurred in Type I and Type II, and most of the provinces still remained in the previous state. Meanwhile, according to the calculation results of the spatial stability index, the value of spatial stability of Moran I scatter plots during the periods 2004-2008, 2008-2012, and 2012-2016 were 0.77, 0.87, 0.90 and 0.9393 , respectively. Meanwhile, the value of spatial stability index showed an upward trend. These results indicated that the spatial distribution characteristics of carbon emissions efficiency in China's transport sector were shown to be highly stable and presented the characteristics of certain path-dependence or the spatial lock-in effect during the study period. The results indicated that it was difficult for most provinces to break away from the original agglomeration area.

Table 3. Space-time transition matrices.

\begin{tabular}{|c|c|c|c|}
\hline Type & 2004-2008 & $2008-2012$ & $2012-2016$ \\
\hline Type I & $\begin{array}{c}H H \rightarrow L H: \text { Zhejiang } \\
L H \rightarrow H H: \text { Jiangsu, Inner Mongolia } \\
L L \rightarrow H L: \text { Hunan }\end{array}$ & $\begin{array}{c}H H \rightarrow L H: \text { Shanghai } \\
L H \rightarrow H H: \text { Jilin }\end{array}$ & $H H \rightarrow L H:$ Beijing \\
\hline Type II & $\begin{array}{c}H L \rightarrow H H: \text { Shanghai } \\
L L \rightarrow L H: \text { Hubei }\end{array}$ & $L L \rightarrow L H:$ Ningxia, Shaanxi & $H H \rightarrow H L:$ Fujian \\
\hline Type III & $H L \rightarrow L H:$ Shanghai & None & None \\
\hline Type 0 & $\begin{array}{c}\text { The remaining } \\
23 \text { provinces }\end{array}$ & $\begin{array}{c}\text { The remaining } \\
26 \text { provinces }\end{array}$ \\
\hline Spatial stability index & 0.77 & 0.87 & 0.93 \\
\hline
\end{tabular}


Table 4. Estimation results of non-spatial panel model.

\begin{tabular}{|c|c|c|c|c|}
\hline Determinants & Pooled OLS & Spatial fixed effects & $\begin{array}{c}\text { Time-period fixed } \\
\text { effects }\end{array}$ & $\begin{array}{c}\text { Spatial and time-period } \\
\text { fixed effects }\end{array}$ \\
\hline Intercept & $-0.3412^{* *}(-2.1719)$ & & & \\
\hline $\ln P G D P$ & $-0.1597^{* * *}(-3.3260)$ & $-0.2581^{* * *}(-8.0848)$ & $0.2654^{* * *}(3.8386)$ & $0.2868^{* * *}(4.6231)$ \\
\hline $\ln U R$ & $0.1014(0.8771)$ & $-0.1018(-1.3472)$ & $-0.1151(-1.0236)$ & $-0.0781(-1.3012)$ \\
\hline $\ln T I$ & $-0.4352^{* * *}(-8.2840)$ & $-0.2656^{* * *}(-5.7815)$ & $-0.4362^{* * *}(-8.5252)$ & $-0.5018^{* * *}(-12.2744)$ \\
\hline $\ln T E I$ & $-0.5816^{* * *}(-12.7692)$ & $-0.3651^{* *}(-8.7109)$ & $-0.6225^{* * *}(-14.3564)$ & $-0.4980^{* * *}(-14.2013)$ \\
\hline $\ln T S S$ & $-0.1087^{* * *}(-4.4722)$ & $0.0795^{* * *}(3.2179)$ & $0.0099(0.3404)$ & $0.0112(0.4847)$ \\
\hline $\ln T E C S$ & $0.0225^{* * *}(2.7269)$ & $0.0170^{* *}(2.0878)$ & $0.0150^{*}(1.9023)$ & $0.01277^{* *}(1.9804)$ \\
\hline$\sigma^{2}$ & 0.0886 & 0.0188 & 0.0761 & 0.0111 \\
\hline$R^{2}$ & 0.5431 & 0.9088 & 0.6129 & 0.9476 \\
\hline Log-likelihood & -92.8267 & 234.0911 & -49.7078 & 345.547 \\
\hline LM spatial lag & $92.7156^{* * *}$ & $16.3397^{* * *}$ & $31.6592^{* * *}$ & 1.1347 \\
\hline LM spatial error & $66.4462^{* * *}$ & $27.0930^{* * *}$ & $8.9837^{* * *}$ & 0.1069 \\
\hline Robust LM spatial lag & $26.5196^{* * *}$ & $3.6618^{*}$ & $29.2879^{* * *}$ & 2.4711 \\
\hline Robust LM spatial error & 0.2501 & $14.4152^{* * *}$ & $6.6124^{* *}$ & 1.4433 \\
\hline
\end{tabular}

Notes: the number in parentheses represent t-stat values. The symbol * denotes $\mathrm{P}<0.1, * *$ denotes $\mathrm{P}<0.05, * * *$ denotes $\mathrm{P}<0.01$.

\section{Spatial Econometric Estimation Results}

Due to the existence of spatial autocorrelation, the classical econometric model may lead to estimation bias of the regression results. Therefore, this paper examined the dominant influencing factors of transport sector carbon emission efficiency by spatial econometric approaches. Following the test procedures described in Table 4, the null hypothesis that the joint significance of spatial fixed effects (818.8533, with 30 degrees of freedom, $\mathrm{P}=0.0000<0.01$ ) and time-period fixed effects (235.6161, with 13 degrees of freedom, $\mathrm{P}=0.0000<0.01$ ) were both rejected under the $1 \%$ significance level. In other words, the spatial and time-period fixed effects were more suitable to fitting the non-spatial panel model. Meanwhile, as for the LM tests, the results showed that, under the $1 \%$ significance level, the null hypotheses of no spatial lag term and the null hypotheses of no spatial error term were both rejected, except for the spatial and time-period fixed effects. As for the robust LM tests, the results showed that the null hypothesis of no spatial lag term and no spatial error for the spatial fixed effects were rejected under the $10 \%$ and $1 \%$ significance levels, respectively. The null hypothesis of no spatial lag term and no spatial error for the time-period fixed effects were rejected under the $1 \%$ and $5 \%$ significance levels, respectively. These results further showed that the spatial econometric models are better than the traditional mixed panel models and it needed to provide more evidence to determine which spatial econometric model should be chosen.

As shown in Table 5, according to results of the Wald test and LR test, the first hypothesis $\left(H_{0}: \phi=0\right)$ and the second hypothesis $\left(H_{0}: \phi+\varphi\right.$ - $\beta=0)$ for the spatial fixed effects and time-period fixed effects could both be rejected under the $1 \%$ significance level, and for the spatial and time-period fixed effects, the first hypothesis and the second hypothesis could be rejected, as well, under the 5\% significance level. The results showed that the spatial Durbin model cannot be simplified. Meanwhile, the Houseman test was used to examine whether the spatial

Table 5. Diagnostic tests of spatial specification.

\begin{tabular}{|c|c|c|c|}
\hline Determinants & Spatial fixed effects & Time-period fixed effects & Spatial and time-period fixed effects \\
\hline Wald test spatial lag & $184.2826^{* * *}$ & $104.4423^{* * *}$ & $13.9419^{* *}$ \\
\hline LR test spatial lag & $160.8217^{* * *}$ & $98.1052^{* * *}$ & $14.7506^{* *}$ \\
\hline Wald test spatial error & $107.2481^{* * *}$ & $120.8932^{* * *}$ & $14.1381^{* *}$ \\
\hline LR test spatial error & $146.9906^{* * *}$ & $116.6127^{* * *}$ & $15.5367^{* *}$ \\
\hline
\end{tabular}

Notes: The symbol * denotes $\mathrm{P}<0.1, * *$ denotes $\mathrm{P}<0.05, * * *$ denotes $\mathrm{P}<0.01$. 
Table 6. Estimation results of spatial Durbin model.

\begin{tabular}{|c|c|c|c|}
\hline Determinants & Spatial fixed effects & Time-period fixed effects & Spatial and time-period fixed effects \\
\hline $\ln P G D P$ & $0.3261^{* * *}(4.3630)$ & $0.3217^{* * *}(4.7361)$ & $0.2736^{* * *}(3.8730)$ \\
\hline $\ln U R$ & $0.0037(0.0590)$ & $-0.2481^{* *}(-2.3401)$ & $-0.0563(-0.9204)$ \\
\hline $\ln T I$ & $-0.4153^{* * *}(-9.7992)$ & $-0.3261^{* * *}(-6.4087)$ & $-0.5008^{* * *}(-12.1363)$ \\
\hline $\ln T E I$ & $0.4467^{* * *}(-12.4562)$ & $-0.4571^{* * *}(-10.1754)$ & $-0.0047^{*}(-1.7848)$ \\
\hline $\ln T S S$ & $0.0065(0.2743)$ & $0.1502^{* * *}(4.7654)$ & $0.0130^{* *}(1.9702)$ \\
\hline $\ln T E C S$ & $0.0114^{*}(1.6782)$ & $0.0302^{* * *}(3.0749)$ & $-0.0391(-0.3355)$ \\
\hline$W^{*} \ln P G D P$ & $-0.3025^{* * *}(-3.6734)$ & $0.0338(0.2281)$ & $-0.2932^{*}(-1.8557)$ \\
\hline$W^{*} \ln U R$ & $-0.2539(-1.5956)$ & $1.3293^{* * *}(5.1796)$ & $0.1254^{* *}(2.3108)$ \\
\hline$W^{*} \ln T I$ & $0.6733^{* * *}(10.0461)$ & $-0.4169^{* * *}(-3.7141)$ & $0.1303(1.5153)$ \\
\hline$W^{*} \ln T E I$ & $0.5612^{* * *}(9.1283)$ & $-0.2718^{* * *}(-2.8496)$ & $-0.0561(-1.1995)$ \\
\hline$W^{*} \ln T S S$ & $0.0723^{* *}(2.2380)$ & $0.0853(1.2573)$ & $0.0281^{* *}(2.1190)$ \\
\hline$W^{*} \ln T E C S$ & $0.0179(1.3914)$ & $-0.0354^{* *}(-2.4372)$ & 0.0107 \\
\hline$\sigma^{2}$ & 0.0124 & 0.0605 & 0.9495 \\
\hline$R^{2}$ & 0.9399 & 0.6922 & 352.9224 \\
\hline Log-likelihood & 314.5020 & -0.6552 & $* 1407$ \\
\hline
\end{tabular}

Notes: the number in parentheses represents t-stat values. The symbol * denotes $\mathrm{P}<0.1$, ** denotes $\mathrm{P}<0.05$, *** denotes $\mathrm{P}<0.01$.

Durbin model with random effects was better than the fixed effects or not. The result showed that the Hausman test did not pass the significance test at the $5 \%$ level (23.7696, with 13 degrees of freedom, $\mathrm{P}=0.0333<0.05)$. Therefore, we chose the spatial Durbin model with fixed effects to analyze the driving factors of the transport sector carbon emissions efficiency. Additionally, based on the results of $R^{2}$ and log-likelihood, the spatial Durbin model with spatial and time-period fixed effects was selected. The estimation results of spatial Durbin model are shown in Table 6.

As shown in Table 6, the per-capita GDP had a positive impact on province-level transport sector carbon emissions efficiency. The coefficient of PGDP was 0.2736 and passed the significance test at the $1 \%$ level. The probable reason for this result is that China's transportation industry is in a downward phase under an inverted U-shaped curve according to the environmental Kuznets curve hypothesis. Some empirical studies have indicated that the relationship between economic growth and transport sector carbon emissions has become decoupled in China [53]. As pointed out by Wei et al. [54], the development of the economy is accompanied by higher economic efficiency relative to the less inefficient carbon emissions. In other words, when the level of economic development is higher, the people can pay more attention to environmental protection, and the government also has a higher ability to develop a low-carbon economy [55].

Urbanization had a negative impact on provincelevel transport sector carbon emissions efficiency, which was consistent with our expectations. The urbanization rate in China increased from $41.7 \%$ in 2004 to $56.65 \%$ in 2016. Urbanization means the population is shifting from rural areas to urban areas, and this may lead to three main impacts on carbon emissions in the transport sector [8]: Firstly, with the increase of the urban population, the number of vehicles, especially for civil car ownership, will increase accordingly. Secondly, with the development of urbanization, it certainly brings the flow for the passenger and freight in space and leads to an increase of carbon emissions and energy consumption in the transport sector [56]. Finally, with the increase of the social-economic activities in the growth process of urbanization, it may lead to more frequent vehicle use, and it will also lead to more energy consumption in the transport sector. Meanwhile, compared to the other transportation modes, such as railways and waterways, the carbon emissions efficiency of cars is relatively lower. Therefore, urbanization may lead to lower carbon emissions efficiency in the transport sector to some extent.

Transportation intensity had a negative impact on province-level transport sector carbon emissions efficiency. The coefficient of TI was -0.5008 and passed the significance test at the $1 \%$ level. Some studies have proven that the improvement of transportation intensity is an important driving factor to carbon emissions reduction. However, compared to the year 2004, in 2016 , transportation intensity decreased by $26.7 \%$. The downward trend of the transportation intensity means the deterioration of the transport sector efficiency and 
makes a positive contribution to carbon emissions in the transport sector [23]. Therefore, achieving progress in transportation intensity is beneficial to improving economic efficiency in the transport sector.

Transportation energy intensity had a negative impact on province-level transport sector carbon emissions efficiency. The coefficient of TEI was -0.4993 and passed the significance test at the $1 \%$ level. Generally speaking, the improvement in transportation energy intensity has a positive role in promoting the transport sector carbon emissions efficiency. However, compared to the year 2004, in 2016 the transportation energy intensity decreased by $20.5 \%$. That is, the efficiency of energy utilization in the transport sector had a downward trend in the observation period. This result may be due to the low level of low-carbon technology in China's transportation industry [34].

The transportation service structure had a negative impact on province-level transport sector carbon emissions efficiency. The coefficient of TSS was -0.0047 and passed the significance test at the $10 \%$ level. This is mainly due to the rapid growth of the proportion of highway comprehensive transportation service to the total comprehensive transportation service (from $11.6 \%$ in 2004 to $31.6 \%$ in 2016). Meanwhile, compared to 2004, the freight kilometers of civil aviation transportation increased 12 times, and the proportion of passenger kilometers of civil aviation transportation increased from $10.59 \%$ in 2004 to $26.8 \%$ in 2016 . However, compared to rail and waterway transportation, highway and civil aviation transportation have higher energy consumption intensities and relatively lower carbon emissions efficiencies [57]. Therefore, optimizing the transportation structure would be an important way to improve the transport sector carbon emissions efficiency.

The transportation energy consumption structure was positively associated with province-level transport sector carbon emissions efficiency. Compared to 2004, in 2016 the proportion of coal consumption in China's transport sector decreased 4.5 times, from $3.91 \%$ in 2004 to $0.87 \%$ in 2016 . The coefficient of TECS was 0.0130 and passed the significance test at the $5 \%$ level. The improvement of the energy structure has an important inhibitory effect on carbon emissions in the transport sector [58]. Therefore, reducing coal consumption could be an effective way to improve carbon emissions efficiency in the transport sector.

\section{Conclusions and Policy Implications}

Geography is an important issue that cannot be neglected in the research of energy and the environment. However, there was little literature concerned with the spatial spillover effects on China's transport sector carbon emissions. For that, this paper investigated the temporal-spatial pattern and influencing factors of carbon emissions efficiency in China's transport sector by using the panel data covering the 30 provincial regions during the period 2004-2016. The empirical results are shown below.

The results indicated that carbon emissions efficiency in China's transport sector was low during the research period, the improvement of the carbon emissions efficiency played an important role in reducing transport sector carbon emissions. Meanwhile, China's provincial transport sector carbon emissions efficiency had an obvious difference, with the quartile graphs of transport carbon emissions efficiency indicating that the spatial distribution characteristics of transport sector carbon emissions efficiency can be described as "high in the east and low in the west". The disparity of carbon emissions efficiency is closely related to the disparity of the provincial socio-economic development level. However, the simple descriptive statistical analysis is difficult to fully extract the different characteristics of carbon emissions efficiency, so we further employed the method of Moran I index to mine the spatial dependence of transport carbon emissions efficiency. The global Moran I index indicated that transport carbon emissions efficiency in China presented a significant positive spatial dependence. Furthermore, approximately $70 \%$ of the provinces belonged to the $\mathrm{HH}$ and LL agglomeration areas. Meanwhile, the provinces in quadrant I were mainly distributed in the eastern and central regions, whereas the provinces in quadrant III were mainly distributed in the western region. Combined with the space-time transition matrices, the results indicated that the spatial distribution of carbon emissions efficiency in China's transport sector presented the characteristics of path-dependence effect to some extent.

Due to the existence of spatial autocorrelation among the provinces of the transport sector carbon emissions efficiency, the classical econometric model may lead to the estimation bias on regression results, so the spatial econometric models are more appropriate than the conventional estimation techniques. Through the related test procedure, we chose the spatial Durbin model with spatial and time-period fixed effects to analyze the driving factors of the transport sector carbon emissions efficiency. The regression results indicated that the per-capita GDP and transportation energy consumption structure had significantly positive effects on transport sector carbon emissions efficiency, whereas the urbanization, transportation intensity, transportation energy intensity, and transportation service structure had negative effects on transport sector carbon emissions efficiency.

Based on the relevant conclusions, some feasible policy recommendations to further improve the transport sector carbon emissions efficiency in China are proposed. Firstly, it is essential to take the remarkable regional disparity into consideration when formulating energy policy. The empirical results indicate that the transport sector carbon emissions efficiency presented an obvious difference at the provincial 
level. Meanwhile, the results of space-time transition matrices indicate that it was difficult for most provinces to break away from the original agglomeration area, thereby there are some differences in the pressure of $\mathrm{CO}_{2}$ emissions reduction faced by China's provincial transport sector. Therefore, it is rather important to formulate differentiated transportation carbon emissions reduction policies based on the economic development level, industrial structure, resource endowment, and technology level in different provinces. Secondly, the spatial spillover should be considered in policy-making toward transport sector carbon emissions abatement. The relevant results have identified the spatial spillover of China's transport sector carbon emissions efficiency, which indicates that improving the transport sector carbon emissions efficiency in a province has positive externalities to the neighboring provinces. Therefore, the government should strengthen cooperation on energy-saving and carbon emissions reduction in the transportation industry. Thirdly, the strategy of urbanization development should be compatible with transportation development. It is a fact that China has become the world's largest vehicle consumer. Private cars are the major contributor to carbon emissions in the transport sector [59]. Therefore, encouraging the development of public transportation, controlling the travel of private cars properly, and guiding private car travel to public transportation are practical approaches. The measures not only can reduce energy consumption in the process of urbanization, but can also alleviate traffic congestion to some extent. Fourthly, Not only should the technology updates be highlighted, but so too should the model shift of fuel consumption. The progress of low-carbon technologies has a significant positive effect on improving carbon emissions efficiency [48]. Since the main low-carbon technology used in China is at a lower level, the government should encourage the investment in $R \& D$ of the relevant low-carbon technologies in the transport sector. Meanwhile, although the proportion of coal consumption is decreasing, fossil energy consumption still plays a dominant role in the transport sector; clean energy still occupies a very small proportion, so some measures to promote the model shift of fuel consumption should be adopted. Finally, the optimization of the transportation service structure should be further highlighted. Compared to highway transportation, railway and waterway transportation are more environmentally friendly. A feasible approach to optimize the transportation service structure is to draw on the experience of the European Union's Marco Polo program, which mainly aims to mitigate environmental pollution of the transportation system by facilitating the model shift of freight from highway to railway and waterway transportation. Therefore, the government should encourage the development of intermodal transport, especially for western and central provinces, such as Yunnan, Ningxia, Jiangxi, Anhui, Henan, and Sichuan (the provinces that have a higher value in transportation service structure). Overall, optimizing the transportation service structure has an important significance to the transport sector carbon emissions reduction.

\section{Acnowledgements}

This research was supported by National Social Science Foundation of China (17BJY139) and the Fundamental Research Funds for the Central Universities (310823160426).

\section{Conflict of Interest}

The authors declare no conflict of interest.

\section{References}

1. GREGG J.S., ANDRES R.J., MARLAND G. China: Emissions pattern of the world leader in $\mathrm{CO}_{2}$ emissions from fossil fuel consumption and cement production. Geophysical Research Letters, 35 (8), 135, 2008.

2. ZHANG N., WEI X. Dynamic total factor carbon emissions performance changes in the Chinese transportation industry. Applied Energy, 146, 409, 2015.

3. WU J., ZHU Q.Y., CHU J.F., LIU H.W., LIANG L. Measuring energy and environmental efficiency of transportation systems in China based on a parallel DEA approach. Transportation Research Part D: Transport and Environment, 48, 460, 2016.

4. WANG S.J., LIU X.P., ZHOU C.S., HU J.C., OU J.P. Examining the impacts of socioeconomic factors, urban form, and transportation networks on $\mathrm{CO}_{2}$ emissions in China's megacities. Applied Energy, 185, 189, 2017.

5. TIMILSINA G.R., SHRESTHA A. Transport sector $\mathrm{CO}_{2}$ emissions growth in Asia: Underlying factors and policy options. Energy Policy, 37 (11), 4523, 2009.

6. LIN B.Q., XIE C.P. Reduction potential of $\mathrm{CO}_{2}$ emissions in China's transport industry. Renewable and Sustainable Energy Reviews, 33, 689, 2014.

7. JEBARAJ S., INIYAN S. A review of energy models. Renewable and Sustainable Energy Reviews, 10 (4), 281, 2006.

8. LIU Z., WU D., YU H., MA W., JIN G. Field measurement and numerical simulation of combined solar heating operation modes for domestic buildings based on the Qinghai-Tibetan plateau case. Energy and Buildings, 167, 312, 2018.

9. LIU Z., LI H., LIU K., YU H., CHENG K. Design of highperformance water-in-glass evacuated tube solar water heaters by a high-throughput screening based on machine learning: A combined modeling and experimental study. Solar Energy, 142, 61, 2017.

10. CHEN W., YANG R. Evolving Temporal-Spatial Trends, Spatial Association, and Influencing Factors of Carbon Emissions in Mainland China: Empirical Analysis Based on Provincial Panel Data from 2006 to 2015. Sustainability, 10 (8), 2809, 2018.

11. QING P.W. Regional Correlation and Spatial Spillovers in China's Regional Economic Growth. Social Sciences in China, 34 (3), 125, 2013. 
12. CHUAI X., HUANG X., WANG W., WEN J., CHEN Q., PENG J. Spatial econometric analysis of carbon emissions from energy consumption in China. Journal of Geographical Sciences, 22 (4), 2012.

13. ANG B.W. Is the energy intensity a less useful indicator than the carbon factor in the study of climate change? Energy Policy, 27 (15), 943, 1999.

14. SUN J.W. The decrease of $\mathrm{CO} 2$ emission intensity is decarbonization at national and global levels. Energy Policy, 33 (8), 975, 2005.

15. CHANG Y.T., ZHANG N., DANAO D., ZHANG N. Environmental efficiency analysis of transportation system in China: A non-radial DEA approach. Energy Policy, 58, 277, 2013.

16. LIU H.W., ZHANG Y., ZHU Q.Y., CHU J.F. Environmental efficiency of land transportation in China: A parallel slackbased measure for regional and temporal analysis. Journal of Cleaner Production, 142, 867, 2017.

17. ZHOU G.H., CHUNG W., ZHANG Y.X. Measuring energy efficiency performance of China's transport sector: A data envelopment analysis approach. Expert Systems with Applications, 41 (2), 709, 2014.

18. GREENING L.A., TING M., DAVIS W.B. Decomposition of aggregate carbon intensity for freight: trends from 10 OECD countries for the period 1971-1993. Energy Economics, 21 (4), 331, 1999.

19. MAZZARINO M. The economics of the greenhouse effect: evaluating the climate change impact due to the transport sector in Italy. Energy Policy, 28 (13), 957, 2000.

20. TIMILSINA G.R., SHRESTHA A. Factors affecting transport sector $\mathrm{CO}_{2}$ emissions growth in Latin American and Caribbean countries: An LMDI decomposition analysis. International Journal of Energy Research, 33 (4), 396, 2009.

21. ANDREONI V., GALMARINI S. European $\mathrm{CO}_{2}$ emission trends: A decomposition analysis for water and aviation transport sectors. Energy, 45 (1), 595, 2012.

22. ACHOUR H., BELLOUMI M. Decomposing the influencing factors of energy consumption in Tunisian transportation sector using the LMDI method. Transport Policy, 52, 64, 2016.

23. WANG W.W., ZHANG M., ZHOU M. Using LMDI method to analyze transport sector $\mathrm{CO}_{2}$ emissions in China. Energy, 36 (10), 5909, 2011

24. LOO B.P.Y., LI L.N. Carbon dioxide emissions from passenger transport in China since 1949: Implications for developing sustainable transport. Energy Policy, 50 (6), 464, 2012.

25. TALBI B. $\mathrm{CO}_{2}$ emissions reduction in road transport sector in Tunisia. Renewable and Sustainable Energy Reviews, 69, $232,2017$.

26. ZHANG C.G., NIAN J. Panel estimation for transport sector $\mathrm{CO}_{2}$ emissions and its affecting factors: A regional analysis in China. Energy Policy, 63 (4), 918, 2013.

27. LIAO C.H., LU C.S., TSENG P.H. Carbon dioxide emissions and inland container transport in Taiwan. Journal of Transport Geography, 19 (4), 722, 2011.

28. LESAGE J.P., PACE, P.K. Introduction to Spatial Econometrics. CCR Press, NewYork, 2009.

29. TOBLER W.R. A Computer Movie Simulating Urban Growth in the Detroit Region. Economic Geography, 46 (sup1), 234, 1970.

30. BURNETT J.W., BERGSTROM J.C., DORFMAN J.H. A spatial panel data approach to estimating U.S. state-level energy emissions. Energy Economics, 40 (2), 396, 2013.
31. DU Q., WU M., WANG N., BAI L. Spatiotemporal Characteristics and Influencing Factors of China's Construction Industry Carbon Intensity. Polish Journal of Environmental Studies, 26 (6), 2507, 2017.

32. ZHAO X.T., BURNETT J.W., FLETCHER J.J. Spatial analysis of China province-level $\mathrm{CO}_{2}$ emission intensity. Renewable and Sustainable Energy Reviews, 33, 1, 2014.

33. LIIMATAINEN H., PÖLLÄNEN M. Trends of energy efficiency in Finnish road freight transport 1995-2009 and forecast to 2016. Energy Policy, 38 (12), 7676, 2010.

34. ZHANG N., ZHOU P., KUNG C.C. Total-factor carbon emission performance of the Chinese transportation industry: A bootstrapped non-radial Malmquist index analysis. Renewable and Sustainable Energy Reviews, 41, 584, 2015.

35. ZHOU G.H., CHUNG W., ZHANG X.L. A study of carbon dioxide emissions performance of China's transport sector. Energy, 50 (1), 302, 2013.

36. TONE K. A slacks-based measure of efficiency in data envelopment analysis. European Journal of Operational Research, 130 (3), 498, 2001.

37. ZHANG J.R., ZENG W.H., WANG J.N., YANG F.L., JIANG H.Q. Regional low-carbon economy efficiency in China: analysis based on the Super-SBM model with $\mathrm{CO}_{2}$ emissions. Journal of Cleaner Production, 163, 202, 2017.

38. LI H., FANG K., YANG W., WANG D., HONG X. Regional environmental efficiency evaluation in China: Analysis based on the Super-SBM model with undesirable outputs. Mathematical and Computer Modelling, 58 (5), 2013.

39. BIAN Y., YANG F. Resource and environment efficiency analysis of provinces in China: A DEA approach based on Shannon's entropy. Energy Policy, 38(4), 1909, 2010.

40. SHI G.M., BI J., WANG J.N. Chinese regional industrial energy efficiency evaluation based on a DEA model of fixing non-energy inputs. Energy Policy, 38 (10), 6172, 2010.

41. CHANG Y.-T., ZHANG N., DANAO D., ZHANG N. Environmental efficiency analysis of transportation system in China: A non-radial DEA approach. Energy Policy, 58, 2013.

42. CHANG Y.T., ZHANG N., DANAO D., ZHANG N. Environmental efficiency analysis of transportation system in China: A non-radial DEA approach. Energy Policy, 58 (9), 277, 2013.

43. HOLTZ-EAKIN D., SELDEN T.M. Stoking the fires? $\mathrm{CO}_{2}$ emissions and economic growth. Journal of Public Economics, 57 (1), 85, 1995.

44. WANG S.J., LI Q.Y., FANG C.L., ZHOU C.S. The relationship between economic growth, energy consumption, and $\mathrm{CO}_{2}$ emissions: Empirical evidence from China. Science of The Total Environment, 542, 360, 2016.

45. MADLENER R., SUNAK Y. Impacts of urbanization on urban structures and energy demand: What can we learn for urban energy planning and urbanization management? Sustainable Cities and Society, 1 (1), 45, 2011.

46. YU J.D., Y.B. Analysis of Carbon emissions changes in China's transportation industry based on LMDI decomposition method. China Journal of Highway \& Transport, 28 (10), 112, 2015.

47. ZHANG W., LI K., ZHOU D.Q., ZHANG W.R., GAO $\mathrm{H}$. Decomposition of intensity of energy-related $\mathrm{CO}_{2}$ emission in Chinese provinces using the LMDI method. Energy Policy, 92, 369, 2016. 
48. LONG R.Y., SHAO T.X., CHEN H. Spatial econometric analysis of China's province-level industrial carbon productivity and its influencing factors. Applied Energy, 166, 210, 2016.

49. HAO Y., LIU Y., WENG J.H., GAO Y.X. Does the Environmental Kuznets Curve for coal consumption in China exist? New evidence from spatial econometric analysis. Energy, 114, 1214, 2016.

50. ZHANG Q., YANG J., SUN Z., WU F. Analyzing the impact factors of energy-related $\mathrm{CO}_{2}$ emissions in China: What can spatial panel regressions tell us? Journal of Cleaner Production, 161, 1085, 2017.

51. ELHORST J.P. Matlab Software for Spatial Panels. International Regional Science Review, 37 (3), 389, 2012.

52. J. REY S. Spatial Empirics for Regional Economic Growth and Convergence. Geographical Analysis, 33 (3), 2001.

53. ZHAO X.R., ZHANG X., LI N., SHAO S.A., GENG Y. Decoupling economic growth from carbon dioxide emissions in China: A sectoral factor decomposition analysis. Journal of Cleaner Production, 142, 3500, 2017.
54. WEI C., NI J.L., DU L.M. Regional allocation of carbon dioxide abatement in China. China Economic Review, 23 (3), 552, 2012

55. CHOI Y., ZHANG N., ZHOU P. Efficiency and abatement costs of energy-related $\mathrm{CO} 2$ emissions in China: A slacksbased efficiency measure. Applied Energy, 98 (5), 198, 2012.

56. SCHOLL L., SCHIPPER L., KIANG N. $\mathrm{CO}_{2}$ emissions from passenger transport: A comparison of international trends from 1973 to 1992. Energy Policy, 24 (1), 17, 1996.

57. WAGNER D.V., AN F., WANG C. Structure and impacts of fuel economy standards for passenger cars in China. Energy Policy, 37 (10), 3803, 2009.

58. ZHU X.P., LI R.R. An Analysis of Decoupling and Influencing Factors of Carbon Emissions from the Transportation Sector in the Beijing-Tianjin-Hebei Area, China. Sustainability, 9 (5), 722, 2017.

59. XU B., LIN B.Q. Differences in regional emissions in China's transport sector: Determinants and reduction strategies. Energy, 95, 459, 2016. 
